MATEC Web of Conferences 23,01013 (2015)

DOI: $10.1051 /$ matecconf/ 20152301013

(C) Owned by the authors, published by EDP Sciences, 2015

\title{
Simulation data of combustion in P-49 boiler with low- temperature vortex combustion technology
}

\author{
Pavel S. Gergelizhiu ${ }^{1 a}$, Ksenia Y. Scherbakova ${ }^{2}$, Boris V. Lebedev ${ }^{1}$ \\ ${ }^{1}$ National Research Tomsk Polytechnic University, 634050 Tomsk, Russia \\ 2Engineering Center "Teplouniversal" LLC, 634050 Tomsk, Russia
}

\begin{abstract}
Low-temperature vortex combustion technology was researched. FIRE-3D software package was used for combustion simulation in P-49 boiler of Nazarovo power plant with excess air ratio $\alpha=1,072$ and fuel rate $B p=39,444 \mathrm{~kg} / \mathrm{s}$. Aerodynamics, oxygen concentration and temperature fields were calculated and represented in graphical form. Obtained results show necessity of follow up research of combustion technology.
\end{abstract}

\section{Introduction}

Low-temperature vortex combustion technology is one of budding but poorly studied area to research. Present technology is interesting by the next advances: burning and injection stabilization, advanced coefficient of thermal effectiveness, decrease of working area slagging, $\mathrm{SO}_{\mathrm{x}}$ and $\mathrm{NO}_{\mathrm{x}}$ emission abatement.

Researches of efficiency upgrading of power engineering equipment are important today. Lowtemperature vortex combustion technology is one of such technology.

The purpose of this work is investigation of aerodynamics and heat-and-mass transfer in lowtemperature vortex combustion furnace. Simulation was conducted with boiler P-49 of Nazarovo state district power station. Lignite of Nazarovo deposit was used as a fuel [1].

The primary targets of this work are development of P-49 mathematical model, customization of input data and analysis of input data impact on burning processes in furnace.

\section{Object of study}

Mathematical model was made by means of application software package FIRE-3D, which is suitable for operational evaluation of input data impact on combustion [2].

Input data are coal burning characteristics, drier agent temperature, fuel fraction composition and its pattern. Boiler grid was created with burners, downdraft and tertiary blast coordinates according to real geometry of Nazarovo P-49 boiler. Simulation was conducted with excess air ratio $\alpha=1,072$ and fuel rate $\mathrm{Bp}=39,444 \mathrm{~kg} / \mathrm{s}$ and present air regime (table 1 ).

a Corresponding author: offix@bk.ru 
MATEC Web of Conferences

Table 1. P-49 Air regime

\begin{tabular}{|c|l|c|}
\hline № & \multicolumn{1}{|c|}{ Parameter } & $\begin{array}{c}\text { Velocity, } \\
\mathrm{m} / \mathrm{s}\end{array}$ \\
\hline 1 & Primary airflow from burners & 49 \\
\hline 2 & Secondary airstream from burners & 54 \\
\hline 3 & Eventilate airstream from downdraft & 37 \\
\hline 4 & Main airstream from downdraft & 30 \\
\hline 5 & Airstream from lower tier of tertiary blast & 35 \\
\hline 6 & Airstream from middle tier of tertiary blast & 36 \\
\hline
\end{tabular}

\section{Aerodynamics}

There is an aerodynamics of furnace at section of 7 burner in the figure 1. Figure 1 description: A burners, $\mathrm{B}$ - downdraft, $\mathrm{C} 1, \mathrm{C} 2$ - tertiary blast. There is a vortex flow in the bottom of furnace due to interaction of downdraft and tertiary airstreams.

There is an uniform upflow along back in middle and top part of furnace with at a speed of $15-20 \mathrm{~m} / \mathrm{s}$. Speed of upflow along front wall and above burner screen is $5-10 \mathrm{~m} / \mathrm{s}$.

Burner stream moves to the back wall, interacts with airstream from lower tier of tertiary blast and pass into upflow. Flow velocity increases from 5 up to $25 \mathrm{~m} / \mathrm{s}$. Airstream from lower tier of tertiary blast loom large in aerodynamic structuring in the bottom of boiler and intensify particle separation to the back hopper wall. There is a low-temperature flame core in furnace bottom with upper temperature limit $1400{ }^{\circ} \mathrm{C}$.

\section{Temperature}

High temperature zone shows burning area of different fractions in a furnace. Fine fraction combusts in area from burners to back walls, then flow up along $\left(\mathrm{T}=130-1400{ }^{\circ} \mathrm{C}\right)$. Relative coarse fraction $(>200 \mathrm{mkm}$ ) moves to the lower vortex and combusts in vertical area of front wall. Temperature of bottom furnace volume is defined by twirl motion of dispersed coal fractions.

\section{Oxygen concentration}

Oxygen concentration is one of parameters characterizing burning, since fuel oxidation lead to decreasing of oxygen contamination to almost zero. There is a minimal oxygen quantity in furnace bottom (figure 3). So, combustion path of fuel particle can be estimated by a minimal concentration of oxygen. It is assumed that area above burner screen is weakly involved in vortex structure. For this reason fuel supply of this area is limited and high concentration of oxygen shows absence of combustion. Whereas high quantity of oxygen appears in delivery points of airstream and is defined by rate of oxidizer. 


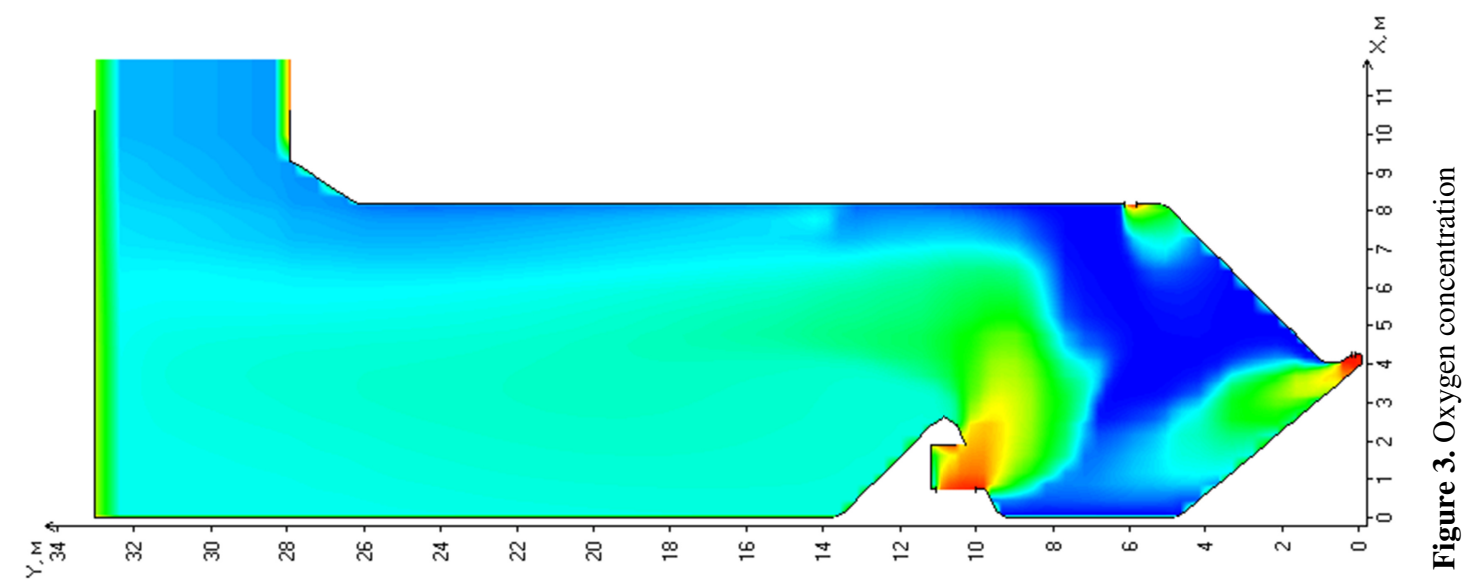

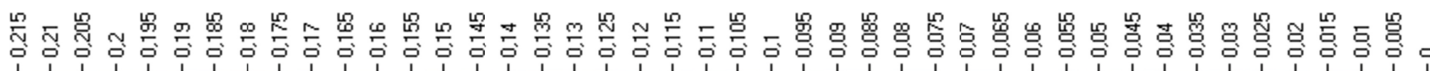

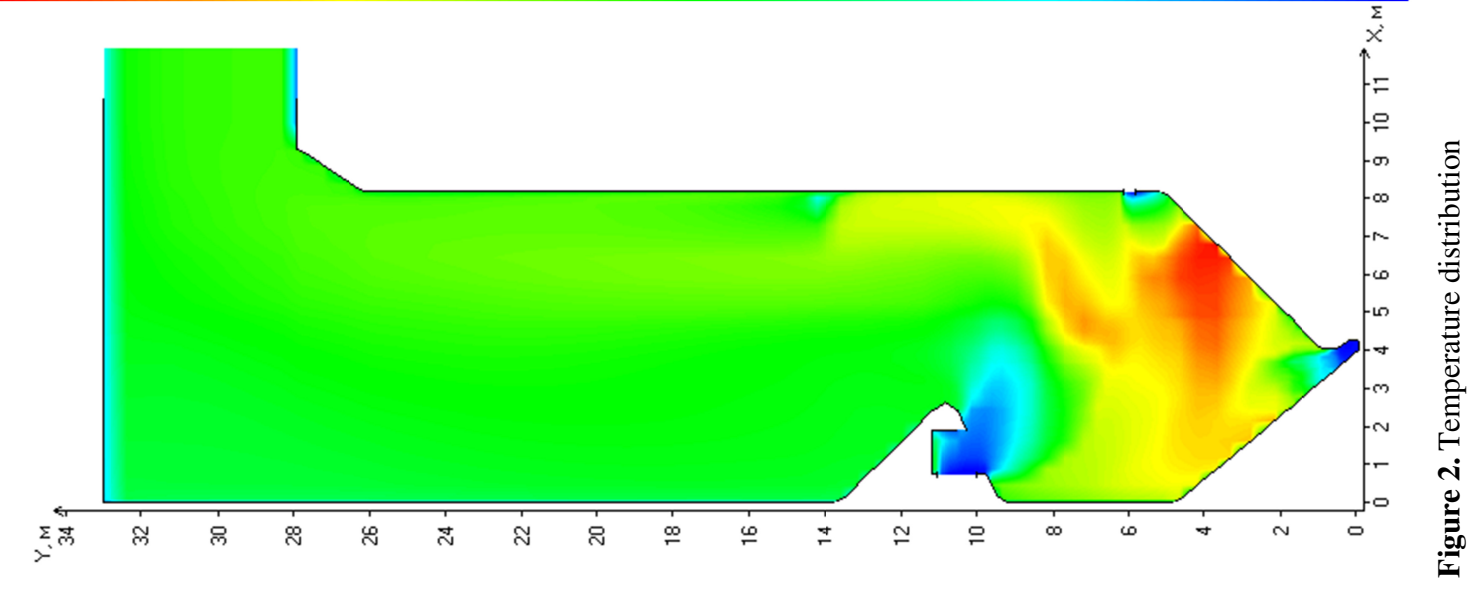

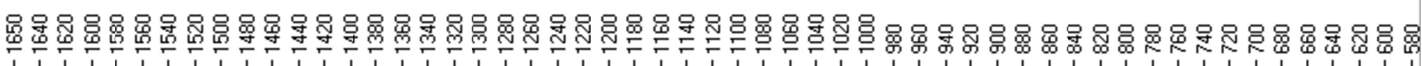

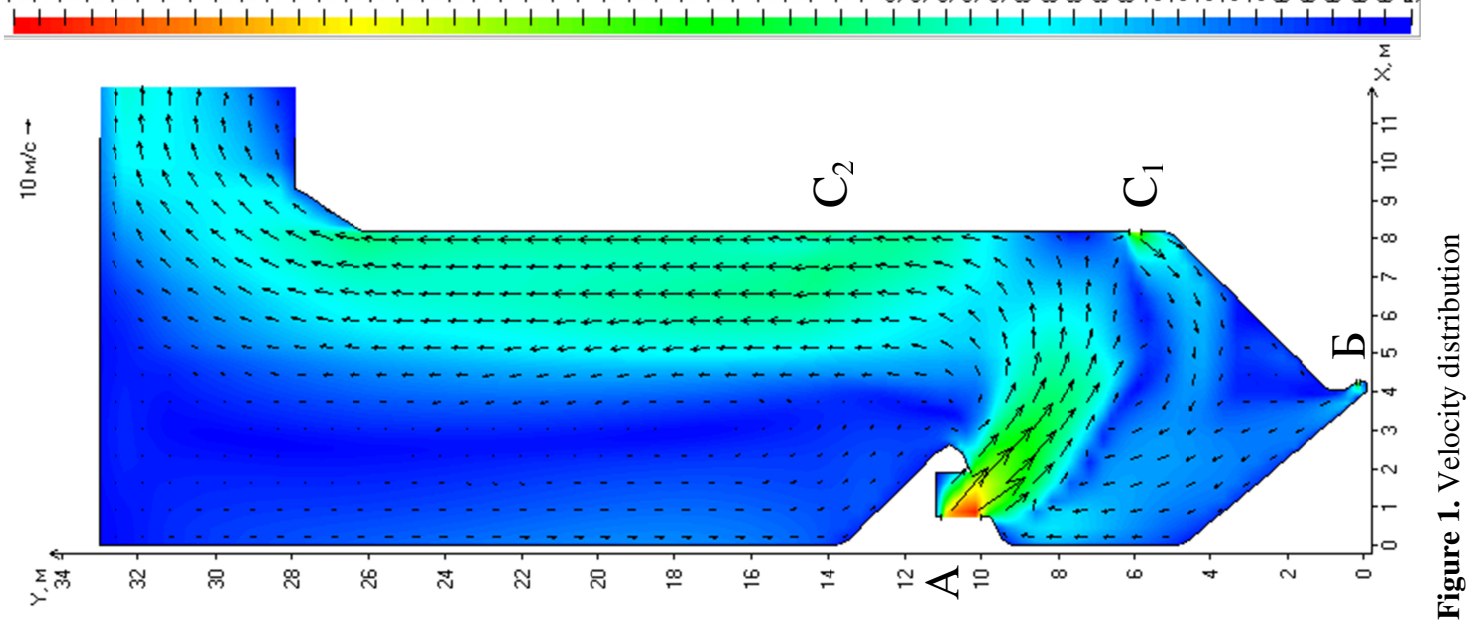

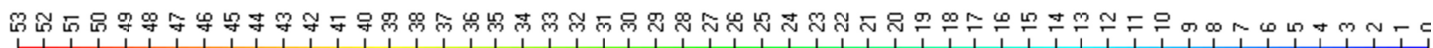


MATEC Web of Conferences

\section{Conclusion}

Results:

1 Mathematical model of P-49 boiler is developed;

2 Input data was customized by means of application software package FIRE-3D;

3 Analysis of input data impact on processes was done;

4 Velocity and temperature diagram and oxygen concentration was obtained in burner section.

Investigation of combustion with simulation shows estimability of velocity, temperature and other characteristics. Structuring of vortex in furnace bottom and oxygen concentration diagram confirm accordance of this model to lowtemperature vortex combustion technology. However air ratio is lower than target value $(\alpha=1.071<1.2)$, therefore current model have need of follow-up study.

\section{References}

1. Teplovoy raschet kotlov (Normativny metod). (Saint-Petersburg: SPO CKTI 1998) [In Russian]

2. A.M. Bubenchikov, A.V. Starchenko Numerical modeling of aerodispersive mixings' dymanic and combustion in channels, 221-234 (1998), ISBN 5-7511-1004-8 [In Russian] 